\title{
Burnout and teaching style among Iranian English language educators in public schools and private institutes: A cross-comparison study
}

\section{Hosseini Fatemi, Azar}

Ferdowsi University of Mashhad, Iran (hfatemi@ferdowsi.um.ac.ir)

Raoufi, Reyhane

Ferdowsi University of Mashhad, Iran (ㄴvoa2008@yahoo.com)

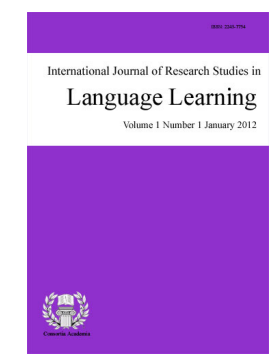

ISSN: $2243-7754$ Online ISSN: 2243-7762

OPEN ACCESS

\section{Abstract}

This study attempts to detect the differences between two groups of teachers; Public school teachers who are permanently employed by government and private institute teachers who work on contract, regarding their level of burnout and their teaching styles. 110 English language teachers from both private and public educational sectors in Mashhad, a city in Northeastern of Iran, participated in this study. Two inventories including Maslach Burnout Inventory (MBI) (1981) and Grasha Teaching Style Inventory (2002) were distributed. Independent-samples t-test suggested a significant difference between burnout level and adoption of teaching styles by school and institute teachers. Finally, with regard to teaching style a significant difference was found between experienced and less-experience teachers.

Keywords: burnout; teaching style; Maslach Burnout Inventory; Grasha's Teaching Style Inventory 


\section{Burnout and teaching style among Iranian English language educators in public schools and private institutes: A cross-comparison study}

\section{Introduction}

Consideration of teachers' role is important because their implementation in the educational process ensures the quality of human and social resources of society (Zlatkovic \& Petrovic, 2011). The quality of teachers' professional activities is influenced by numerous factors. Some authors emphasize the explanatory power of internal factors such as abilities, personality traits, motivation etc. (Bernard, 1972; Deci \& Ryan, 1987) while some others emphasize external factors such as school equipment, legislation etc. (Edmonds, 1983). Burnout is a vital issue that affects teachers' physical and mental health and subsequently will undermine their efficacy. Their inefficacies demotivate learners and finally slack the process of language learning. Burnout was defined as a state of physical, mental, and emotional exhaustion that stemmed from job stress, attrition, and frustration (Maslach, Schaufeli, \& Leiter, 2001).

Maslach and Jackson (1984) identified it as a tridimensional construct comprising Emotional Exhaustion, Depersonalization, and Reduced Personal Accomplishment. Unfortunately burnout is widespread among teachers due to different factors. Each year a number of teachers leave the occupation and those who keep up teaching in spite of their exhaustion would have a negative influence on the quality of education. Although these factors are not completely known to the principals but there should be attempts to find out what they are and what policies should be established in order to slow down the process of burnout, if they are not able to completely stop it. Teaching style is another important issue in educational process which direct teachers' instructional processes that has effects on students and their subsequent ability to learn (Grasha, 2002). Grasha (2002) defines it as "those enduring personal qualities and behaviors that appear in how teachers conduct their classes". He identified five teaching styles including Expert, Formal Authority, Personal Model, Facilitator, and Delegator styles, and created a survey to identify teacher's preferred instruction style (Grasha, 2002).

Work context and environmental factors has been investigated to be contributors to the progression of burnout (Cherniss, 1980a; Shirom, 1987; Whitehead, 2001). This study also suspects that the work settings may direct teachers toward using a particular teaching style. Since education in Iran on language teaching is done by two sectors; public schools and private institutes, this study aims at comparing burnout level and adopted teaching styles in these two language teaching contexts. Furthermore, it is going to detect the difference in adoption of particular style of teaching by groups of teachers with different years of experience.

Following research questions is going to be investigated in current study:

1. Is there a significant difference between Iranian EFL teachers in public and private sectors regarding their burnout level?

2. Is there a significant difference between Iranian EFL teachers in public and private sectors regarding their teaching styles?

3. Is there a significant difference in teaching styles of four groups of Iranian EFL teachers with respect to years of teaching experience?

\section{Burnout}

Literature shows that "burnout" plays a vital role in effecting individual and organizational health. The term became popular when Freudenberger (1974) used it to describe his personal experience from too much work. The notion continued to exist by vast body of studies carried out by Maslach and her colleagues (Maslach \& 
Burnout and teaching style among Iranian English language educators in public schools and private institutes

Jackson, 1981, 1984). Their findings revealed a tridimensional construct comprising emotional exhaustion, Depersonalization, and Reduced Personal Accomplishment. Emotional exhaustion refers to feeling of fatigue resulting from daily conflict in work. Teachers having signs of emotional exhaustion perceive themselves unable to spend much energy as they did earlier. Depersonalization indicates one's negative attitude toward others and feeling of being detached from students, parents and colleagues. Reduced Personal Accomplishment is lacking the feeling of success and efficiency in class environment, so teachers consider themselves incompetent to make student learn. A more recent definition of "Burnout" clarify it as an extreme state of psychological strain and depletion of energy resources arising from prolonged exposure to stressors which exceed an individual resources to cope, particularly associated with human resource professions (Cooper, Dewe, \& Driscoll, 2000).

In study of any construct, measurement has been an important issue. Emotional constructs were used to be assessed through observation, interview or self-report but they were neither systematic nor standardized. Burnout is not an exception. In the late 1970s attempts to develop inventories for assessing levels of burnout were made. The most popular of all is Maslach Burnout Inventory (MBI). As discussed earlier MBI test treat burnout as a three-dimensional syndrome that is characterized by emotional exhaustion, depersonalization and reduced personal accomplishment (Maslatch \& Jackson, 1981, 1986). It's also a self-report inventory containing 22 items, divided into three aforementioned dimensions. Teachers are more prone to burnout due to their emotionally challenging job in comparison to other professions (Maslach, Jackson, \& Leiter, 1996; Schaufeli \& Enzmann, 1998). So many researchers directed their attention to teacher burnout and carried out their studies on impact of background variables on burnout and its relationship with other variables (Byrne, 1991; Bussing \& Perrar, 1992; Mukundan \& Khandeh roo, 2010; Adekola, 2012; Zarei Matin, Seyyed Kalali, \& Akhavan Anvari, 2012).

Researches on demographic variables yielded inconsistent results. Concerning age, Laub (1998) found that among secondary school teachers, younger ones were at greater risk of burnout than their older counterparts. Regarding gender, Schaufeli and Enzmann (1998) confirmed women tended to score higher on emotional exhaustion, while men exceed on depersonalization scores. However, other researchers have found that demographic factors had no effect on experiencing burnout (Dillon \& Tanner, 1995; Friedman \& Farber, 1992). Considering workload, Mukundan and Khandeh roo (2010) suggested those with more than ten hours per week wore out emotionally but the ones with less than 30 hours faced depersonalization and reduced personal accomplishment.

In addition to demographics, individual traits were scrutinized to reveal their possible association with burnout. For example, Layman and Guyden (1997) suggested that introverted people were at higher risk of developing burnout than extroverted people. Another study indicated that teachers with low self-esteem are more susceptible to burnout. Furthermore, teachers' career self-concept was investigated to be negatively correlated with their burnout (Zamani \& Nasir, 2010). Ghorpade, Lackritz, and Singh (2007) found strong relationships between dimensions of burnout and personality traits. Emotional exhaustion was negatively related to extroversion and emotional stability, depersonalization was negatively related to agreeableness and emotional stability, and personal accomplishment was positively related to extroversion, conscientiousness, agreeableness, and emotional stability. In a study done by Schaufeli, Van Dierendonk, and Van Gorp (1996), a connection between burnout and creativity was found.

They found people experiencing burnout are associated by less creativity. Friedman (1995) maintained the close association between burnout and stress and saw stress as the onset of burnout process. Later Fisher (2011) examined the stress, burnout, satisfaction and preventing coping skills of secondary teachers and found a significantly different burnout levels between new and experienced teachers, however their stress levels' difference were not statistically significant. In his study, job satisfaction, preventive coping skills and stress were verified to be statistically significant predictors of burnout.

To find out the major factors leading English language teachers to burnout, a study was conducted by Cephe (2010). In this study, first the levels of teachers' burnout were examined, and then an interview was carried out 
with 12 teachers who were selected randomly. All the instructors having different levels of burnout believe that administrative application is the major cause of their burnout and "alienation to professional identity" is identified as consequence of burnout in which teachers disconnect themselves from the profession and find a non-teaching job. Organizational factors were also classified as the antecedents of job burnout (Cordes \& Dougherty, 1993). Effects of teaching context and unhealthy work environment on levels of burnout have been investigated (Whitehead, 2001). Mandaglio (1984) had previously discussed the impact of institution on burnout. According to him, most experts believe in interaction between individuals and their work settings. Also overload in work context is considered to be an element that may foster burnout. Four factors relating to institution which was determined to foster burnout include pupil misbehavior, time pressures and lack of facilities, not having chance for promotion and poor relationships with colleagues or parents (Boyle, Borg, Falzon, \& Baglioni, 1995).

\section{Teaching Style}

Teaching style has been one of the major concerns in the field of ELT. Teacher training courses that are held for training teachers demonstrates its importance. Kaplan and Kies (1995) defined teaching style as "a teacher's personal behaviors and media demonstrate to transmit data to or receive it from the learner" (p. 29). According to Grasha (2002), there are a variety of "modes of performing" associated with our styles as teachers including such elements as "mental, spiritual, and physical acts"; "speaking, listening, responding"; "voice, gesture, movements"; "facilitating, encouraging"; using a trained eye to see what is actually happening" ; and "the openness we have to questions". He believes that teaching styles affect how teachers present information, interact with students, manage classroom tasks, supervise course work, socialize students to the field, and guide students (Grasha, 2002). The most famous classification of teaching styles categorize them into Expert, Formal Authority, Personal Model, Facilitator, and Delegator styles (Grasha, 2002).

As Grasha (2002) define them, expert style refers to possessing knowledge and expertise that students need. These teachers try to maintain their status among students by displaying their detailed knowledge. Formal authority style is related to possessing status among students because of knowledge where the educational experience tends to be teacher-centered. Teachers are concerned with providing positive and negative feedback, establishing learning goals, expectations, and rules of conduct for students. The personal model style refers to believing in teaching by personal example and establishing a model for how to think and behave. The facilitator style emphasizes the personal nature of teacher-student interaction. They guide and direct students by asking questions, exploring options, suggesting alternatives, and encouraging them to develop criteria to make informed choices and finally delegator teaching style is concerned with developing students' capacity to function in an autonomous fashion where learners receive feedback during the development of a project.

Employing Sternberg's theory of thinking styles (1988, 1997), Zhang and her colleagues (Zhang, 2004; Zhang, Huang, \& Zhang, 2005) investigated the preferred teaching styles among university students in Hong Kong and the United States. Zhang et al.'s (2005) research indicated that university students in both Hong Kong and the United States preferred that their teachers use creativity-generating teaching styles and that they expressed the least interest in teaching styles that are norm-favoring. Furthermore, Zhang's study (2004) suggested that students' preferences in teaching styles varied as a function of their own characteristics, including age, academic disciplines, self-rated abilities, and thinking styles.

Another study done in this area by Zhang (2007) to investigate the predictive power of personality type for teacher's teaching style. Based on empirical data, Zhang and Sternberg (2005) have reconceptualized 13 Thinking Styles in Teaching Inventory into three types. Type I and Type II styles are relevant to his study. Type I thinking styles tend to be more creativity-generating and they denote higher levels of cognitive complexity, including the legislative, judicial, hierarchical, global, and liberal styles. Type II thinking styles suggest a norm-favoring tendency and they denote lower levels of cognitive complexity, including the executive, local, monarchic, and conservative styles. Results suggested that six of the seven teaching styles (with the global teaching style being the exception) were statistically predicted by particular personality trait(s) controlling for 
Burnout and teaching style among Iranian English language educators in public schools and private institutes

teachers' gender, educational level, and their perceptions of the quality of their students (occasionally referred to as the three control variables hereafter).

Four of the five personality traits (with neuroticism being the exception) significantly contributed to the prediction of teaching styles beyond the three control variable (Zhang, 2007). The strongest predictors for teaching styles were the openness and conscientiousness personality traits. As predicted, the openness scale negatively predicted all three Type II teaching styles, while the conscientiousness scale positively predicted three of the four Type I styles. Both the agreeableness scale and the extraversion scale (remember that no specific relationships were anticipated of these two personality traits with particular teaching styles) turned out to be secondary predictors for teaching styles. Agreeableness negatively contributed to the prediction of the judicial teaching style, while extraversion positively contributed to the local teaching style. There is a paucity of research to see whether or not teachers' adoption of teaching styles differs in different work settings. In order to detect existing differences, the current study not only examine burnout level but also inspect teaching styles in two work contexts in Iran; public schools and private institutes.

\section{Methodology}

\subsection{Settings and participants}

This study is conducted in Mashhad; a city in Northeastern of Iran. The participants include 110 English language educators, from both public schools and private institutes. The former group comprises 33.6 percent of the population and the latter comprises 66.4 percent. They range in age from 22 to 50. Although some participants left some items unanswered, they weren't completely excluded from the study. They were excluded only if they were missing the data required for a specific analysis by choosing the exclude cases pairwise option in the SPSS before starting the analysis.

\subsection{Instruments}

Three questionnaires were distributed to collect the data for analysis: A) Demographic questionnaire to get demographic information about participants. B) Maslach's Burnout Inventory (MBI) which includes 22 items having three subscales of emotional exhaustion, depersonalization, and personal accomplishment (Maslach \& Jackson, 1981, 1986). The inventory validation was done in Iran by Filiyan (1992). After translating the original inventory into Persian, the validity was confirmed by some experts in Tarbiat Modarres University and some other in the field of psychology. The Conbach's alpha reliability coefficient for the scale was .709 in the current study. C) Grasha Teaching Style Inventory which is validated by Grasha in 1996 includes 40 items on 7-point Likert-type scale. The responses range from strongly disagree to strongly agree. Each 8 items identifies one of the five basic teaching styles defined by Grasha (1996) regarding expert, formal authority, personal model, facilitator, delegator teaching style. In this study, the Conbach's Alpha was .901

\subsection{Procedure}

After collecting the questionnaires, SPSS 18 (Statistical Package for Social Sciences) was used for inputting data and processing them. Independent-samples t-test determined the discrepancies between public school and private institution teachers with regard to burnout level and adoption of particular teaching styles. Then one-way ANOVA was run to detect any significant differences in teaching styles among teachers with various years of teaching experience.

\section{Results}

To answer the first research question regarding the difference in the mean burnout scores for teachers of public and private sectors, the independent-samples t-test was conducted to compare their total scores for 
Hoseini Fatemi, A. \& Raoufi, R.

burnout. Table 1 indicates the mean scores for three subscales of burnout including emotional exhaustion, personal accomplishment, depersonalization for two groups of teachers, school teachers who are permanently employed by government and those teachers working in institutes on contract. As Table 1 demonstrates, there is a significant difference in the mean scores of emotional exhaustion for school teachers $(M=8.29, \mathrm{SD}=4.41)$ and institute educators $(\mathrm{M}=10.89, \mathrm{SD}=6.64 ; \mathrm{t}(99.1)=-2.4, p=.01$, two-tailed). The magnitude of the differences in the means (mean difference $=-2.6,95 \%$ CI: -4.7 to -.45 ) was moderate (eta squared=.05). Regarding two other dimensions of burnout; personal accomplishment and depersonalization, it can be seen that the mean score difference is not statistically significant $(p>.05)$.

\section{Table 1}

Independent Samples Test of Public and Private Teachers regarding Burnout

\begin{tabular}{llcccccc}
\hline \multicolumn{1}{c}{ Subscales } & \multicolumn{1}{c}{ Job Status } & $N$ & Mean & SD & $t$ & $d f$ & sig \\
\hline Emotional & Public School teachers & 37 & 8.29 & 4.41 & -2.4 & 99.12 & .01 \\
Exhaustion & Private institute teachers & 69 & 10.89 & 6.64 & & & \\
\hline Personal & Public School teachers & 36 & 35.41 & 10.06 & 1.3 & 103 & .18 \\
Accomplishment & Private Institute teachers & 69 & 32.37 & 11.47 & & & \\
\hline Accomplishment & Public School teachers & 35 & 1.54 & 1.46 & -.11 & 97 & .91 \\
& Private Institute teachers & 64 & 1.57 & 1.55 & & & \\
\hline
\end{tabular}

An independent-samples t-test was conducted to answer the second research question probing a significant difference in the teaching styles adopted by teachers of public and private sectors. The total mean scores of five components of teaching styles for two groups of teachers were shown in Table 2. Regarding expert, the sig. value is significant $(<.05)$ and it means that the difference between school teachers $(\mathrm{M}=39.5, \mathrm{SD}=4.88)$ and institution teachers $(\mathrm{M}=36.9, \mathrm{SD}=6.08 ; \mathrm{t}(93)=2.8, p<.05$, two-tailed $)$ are meaningful. The $p$ value for formal authority does not show a significant value (>.05), so the difference between school teachers $(\mathrm{M}=38.09, \mathrm{SD}=$ $6.84)$ and institution teachers $(\mathrm{M}=37.5, \mathrm{SD}=8.79 ; \mathrm{t}(92)=.30, p>.05$, two-tailed $)$ is not statistically significant.

Personal model shows a significant difference between school teachers $(\mathrm{M}=41.81, \mathrm{SD}=6.51)$ and institution teachers $(\mathrm{M}=38.25, \mathrm{SD}=6.54 ; \mathrm{t}(95)=2.54)$ with $\mathrm{p}$ value smaller than .05 . There is also a significant difference between school teachers $(M=42.37, S D=6.92)$ and institution teachers $(M=38.53, S D=7.81 ; t(94)=2.35$, $p<.05)$ with regard to adopting facilitator teaching style. Finally no significant difference is observed between school $(\mathrm{M}=38.84, \mathrm{SD}=6.31)$ and institute teachers $(\mathrm{M}=36.74, \mathrm{SD}=9.14 ; \mathrm{t}(86.6)=1.31, p>.05)$ regarding delegator style.

\section{Table 2}

Independent Samples Test of Public and Private Teachers regarding Teaching Style

\begin{tabular}{|c|c|c|c|c|c|c|c|}
\hline Subscales & Job Status & $N$ & Mean & $S D$ & $t$ & $d f$ & sig \\
\hline \multirow[t]{2}{*}{ Expert } & Public School teachers & 32 & 39.53 & 4.88 & \multirow[t]{2}{*}{2.08} & \multirow[t]{2}{*}{93} & \multirow[t]{2}{*}{.04} \\
\hline & Private institute teachers & 63 & 36.95 & 6.08 & & & \\
\hline \multirow[t]{2}{*}{ Formal Authority } & Public School teachers & 31 & 38.09 & 6.84 & \multirow[t]{2}{*}{.30} & \multirow[t]{2}{*}{92} & \multirow[t]{2}{*}{.76} \\
\hline & Private Institute teachers & 63 & 37.55 & 8.79 & & & \\
\hline \multirow{2}{*}{$\begin{array}{l}\text { Personal } \\
\text { Model }\end{array}$} & Public School teachers & 33 & 41.81 & 6.51 & \multirow[t]{2}{*}{2.54} & \multirow[t]{2}{*}{95} & \multirow[t]{2}{*}{.01} \\
\hline & Private Institute teachers & 64 & 38.25 & 6.54 & & & \\
\hline \multirow[t]{2}{*}{ Facilitator } & Public School teachers & 32 & 42.37 & 6.92 & \multirow[t]{2}{*}{2.35} & \multirow[t]{2}{*}{94} & \multirow[t]{2}{*}{.02} \\
\hline & Private Institute teachers & 64 & 38.53 & 7.81 & & & \\
\hline \multirow[t]{2}{*}{ Delegator } & Public School teachers & 33 & 38.84 & 6.31 & \multirow[t]{2}{*}{1.31} & \multirow[t]{2}{*}{86.68} & \multirow[t]{2}{*}{.19} \\
\hline & Private Institute teachers & 62 & 36.74 & 9.14 & & & \\
\hline
\end{tabular}

To answer the third research question exploring the difference among four groups of teachers having different years of teaching experience with regard to their teaching styles, a one-way ANOVA was run. Participants were divided into four groups according to their years of teaching experience (Group1: 1-5 years; Group2: 5-10 years; Group3: 10-15 years; Group4: 15 years and above). Since there were no significant differences among groups of teachers having different years of experience with regard to formal authority and 
Burnout and teaching style among Iranian English language educators in public schools and private institutes delegator based on results, the tables are not put to save the space. Here only significant differences are depicted. It should be noted that we have not violated the assumption of homogeneity of variances of groups.

Table 3 displays the mean score for expert, personal model and facilitator (as subscales of teaching style) for four groups of teachers with different years of experience. Also the numbers and standard deviations are presented.

Table 3

Descriptive statistics for groups of teachers regarding use of teaching style

\begin{tabular}{lllll}
\hline Subscales & Years of Experience & $N$ & Mean & SD \\
\hline Expert & Group 1: 1-5 years & 50 & 36.66 & 6.28 \\
& Group 2: 5-10 years & 15 & 35.66 & 5.09 \\
& Group 3: 10-15 years & 4 & 40.50 & 4.79 \\
& Group 4: 15-more & 26 & 40.88 & 3.98 \\
\hline Personal & Group 1: 1-5 years & 51 & 37.80 & 6.12 \\
Model & Group 2: 5-10 years & 15 & 36.86 & 6.44 \\
& Group 3: 10-15 years & 4 & 45.00 & 6.05 \\
& Group 4: 15-more & 27 & 43.22 & 6.25 \\
\hline Facilitator & Group 1: 1-5 years & 51 & 37.92 & 7.78 \\
& Group 2: 5-10 years & 15 & 39.06 & 6.76 \\
& Group 3: 10-15 years & 4 & 43.25 & 8.22 \\
& Group 4: 15-more & 26 & 43.42 & 6.92 \\
\hline
\end{tabular}

Table 4 demonstrates 'between group', 'within-groups', 'sums of squares', 'degree of freedom', ' mean square', 'F value' and 'p value'. As it can be seen in Table 4, there were statistically significant differences at the $p<.05$ level in teaching styles (expert, personal model and facilitator) scores adopted by four groups of teachers; for expert, $\mathrm{F}(3,91)=4.49, p=.005$, for personal model $\mathrm{F}(3,93)=6.44, p=.005$ and for facilitator $\mathrm{F}(3,92)=3.48$, $p=.019$

Table 4

Results of One-way ANOVA for groups of teachers regarding use of teaching style

\begin{tabular}{lllllll}
\hline Subscales & & Sum of Squares & $d f$ & Mean Square & $F$ & Sig. \\
\hline Expert & Between Groups & 409.75 & 3 & 136.58 & 4.49 & .005 \\
& Within Groups & 2766.20 & 91 & 30.39 & & \\
& Total & 3175.95 & 94 & & & \\
\hline Personal & Between Groups & 745.68 & 3 & 248.56 & 6.44 & .001 \\
Model & Within Groups & 3588.43 & 93 & 38.58 & & \\
& Total & 4334.12 & 96 & & 3.48 & .019 \\
\hline Facilitator & Between Groups & 576.90 & 3 & 192.30 & & \\
& Within Groups & 5071.71 & 92 & 55.12 & & \\
& Total & 5648.62 & 95 & & & \\
\hline
\end{tabular}

Post-hoc comparisons using the Tukey HSD test indicated that the mean scores of expert for Group 1 (mean=36.66, $\mathrm{SD}=6.28$ ) and Group 2 (mean=35.66, $\mathrm{SD}=5.09$ ) with less experience were significantly different from Group $4($ mean $=40.88, \mathrm{SD}=3.98)$ who are experienced. The mean scores of personal model for Group 1 $($ mean $=37.80, \mathrm{SD}=6.12)$ and Group $2($ mean $=36.86, \mathrm{SD}=6.44)$ who are less experienced were significantly different from Group 4 (mean=43.22, $\mathrm{SD}=6.25$ ) who are experienced. And finally the mean scores of facilitator for Group 1 (mean= 37.92, $\mathrm{SD}=7.78)$ was significantly different from Group 4 (mean= 43.42, SD=6.92).

\section{Conclusion}

This study used independent-sample t-test to differentiate between teachers of public and private sectors with regard to their burnout. The result revealed a significant difference between two groups with regard to their emotional exhaustion. Institute teachers working on contracts showed that they are more exhausted emotionally 
than public schools teachers. But there were no difference between two regarding their personal accomplishment and depersonalization. According to Pishghadam and Sahebjam (2011), teachers at language institutes not only should be proficient in English language but also they should have general information on various areas of knowledge. So they may face stressors when they encounter high expectations of parents, managers and supervisors. Factors which are more prevalent in private sectors and may be the cause of institute teachers' emotional exhaustion are too much workload, too much routine, lack of autonomy, incongruent institutional goals, poor leadership and supervision practices (Cherniss, 1980b). According to Conservation of Resources (COR) model (Hobfoll \& Shriom, 1993), burnout occurs due to the loss of resources such as job stability, wages, and excessive workload. Institute teachers mostly work on temperate contracts so they don't feel safe in work place. Moreover they receive low income which is not consistent with their workload. These factors wear down teacher's energy and may lead to emotional exhaustion.

Another goal of this research was to detect the difference between private institute and public school teachers' teaching style. Unfortunately there seems to be no research project investigating Iranian teachers' teaching style and comparing them. The result of this study demonstrated that school teachers are significantly different with institute teachers in adopting Expert, Personal model and Facilitator style. School teachers use Expert, Personal model and Facilitator style more than institute teachers. To justify the result, it can be said that school teachers have knowledge and proficiency that students need. They maintain their position as a knowledgeable person by displaying their information. That's natural since English books being taught at schools do not demand a high level of proficiency, school teachers feel safer with the amount of expertise they possess. So they act in an expert teaching style. They also tend more to use personal models. Because school teachers have more years of experience in comparison to young institute teachers, they inclined to use their personal example while teaching. After years of teaching experience, they establish standard way of doing things based on their own approach and they know better what a good model for student to emulate is.

Moreover they are experienced enough to interact well with student, guide and direct them by asking questions, exploring options, suggesting alternatives which are characteristics of Facilitator teachers according to Grasha (2002). The role of experience in adoption of a particular style has been confirmed by last research question of the current study. Teachers were divided to four groups based on their years of experience. One-way ANOVA compared the mean scores of these four groups on five mentioned teaching style. The result verified that there is significant difference between less experienced (1-10 years of experience ) and more experienced teachers (more than 15 years of experience) with regard to using teaching styles and that more experienced teachers has higher mean scores in conducting classes with using Expert, Personal model and Facilitators style. As discussed earlier, experience has a great role in the way teachers conduct their classes. More experienced teachers has more familiarity with course materials and act as experts that know well how to transfer information effectively. They have had more chance and experience to develop their own examples and guide students to fulfill their expectations. Experienced teachers have better understanding of students' needs so they know how to explore options to meet their requirements. Furthermore years of encountering with various types of students having particular personal traits let experienced teachers to establish good rapport with them in the process of language learning. Therefore they can be good facilitator teachers.

\subsection{Pedagogical Implications}

This research has identified some of the key contributors to teacher burnout which has several implications for supervisors, textbook designers and teachers themselves. Firstly, since institute teachers experienced higher levels of burnout than school teachers, managers of private institutes should set up a good environment for teachers to hinder any stressors that may emanate from working context. Besides, supervisors should hold workshops for less experienced teachers to encourage adopting facilitator and delegator teaching style which enable teachers to establish mutual relationship with their students, let them cooperate in class by delegating them some tasks. In this way teachers can share the burden of teaching and save their energy that decelerate burnout process. Finally textbook designers should design books which provide teachers with tasks that are 
Burnout and teaching style among Iranian English language educators in public schools and private institutes

suitable for applying such styles. It should be notified that due to the rarity of research on teaching style in Iran, replication of this study with larger population is of great importance to confirm or reject the findings.

\section{References:}

Adekola, B. (2012). Work burnout experience among university non-teaching staff: A gender approach. International Journal Academic Research in Business and Social Sciences, 1, 128-135.

Bernard, W. H. (1972). Psychology of learning and teaching, New York: McGraw Hill Book Company.

Boyle, G. J., Borg, M. G., Falzon, J. M., \& Baglioni, A. J. (1995). A structural model of the dimensions of teacher stress. British Journal of Educational Psychology, 65, 49-67. http://dx.doi.org/10.1111/j.2044-8279.1995.tb01130.x

Byrne, B.M. (1991). Burnout: Investigating the impact of background variables for elementary, Intermediate, secondary university educators. Teaching and teacher and education, 7 (2), 197-209.

Büssing, A., \& Perrar, K. M. (1992). The measurement of burnout: Examination of a German version of the Maslach Burnout Inventory (MBI-D). Diagnostica, 38, 328-353.

Cephe, P. T. (2010). A study of the factors leading English teachers to burnout. Journal of Education, 38, 25-34.

Cherniss, C. (1980a). Staff burnout: job stress in the human services. Beverly Hills, CA: Sage Publication.

Cherniss, C. (1980b). Professional burnout in human service organizations. New York: Praeger.

Cooper, C. L. \& Dewe, P. J., \& O’Driscoll, M. D. (2000). Organizational stress: A review and critique of theory, research and applications. Thousand oaks, California: sage.

Cordes, C., \& Dougherty, T. (1993). A review and integration of research on job burnout. Academy of Management Review, 18, 621-656.

Deci, E. L., \& Ryan, R. M. (1987). The support of autonomy and the control of behavior. Journal of Personality \& Social Psychology, 53, 1024-1037. http://dx.doi.org/10.1037/0022-3514.53.6.1024

Dillon, J. F., \& Tanner, G. R. (1995). Dimensions of career burnout among educators. Journalism and Mass Communication Educator, 50, 4-13. http://dx.doi.org/10.1177/107769589505000201

Edmonds, R.R. (1983). Search for effective schools: The identification and analysis of city schools that are instructionally effective for poor children (final report). East Lasing: Michigan State University.

Filiyan, E. (1992). The examination of burnout and its relationship with coping mechanism in nurses, Unpublished master thesis, Tarbiat Modarres University, Tehran, Iran.

Fisher, M. H. (2011). Factors influencing stress, burnout, and retention of secondary teachers. Current Issues in Education, 14(1). Retrieved from http://cie.asu.edu/

Freudenberger, H. J. (1974). Staff burnout. Journal of Social Issues, 30, 159-165. http://dx.doi.org/10.1111/j.1540-4560.1974.tb00706.x

Friedman, I. A., \& Farber, B. A. (1992). Professional self-concept as a predictor of teacher burnout. The Journal of Educational Research, 86, 28-35. http://dx.doi.org/10.1080/00220671.1992.9941824

Friedman, I. A. (1995). Student behavior patterns contributing to teacher burnout. Journal of Educational Research, 88(5), 281-289. http://dx.doi.org/10.1080/00220671.1995.9941312

Ghorpade, J., Lackritz, J., \& Singh, G. (2007). Burnout and personality: Evidence from academia. Journal of Career Assessment, 15(2), 240-256. http://dx.doi.org/10.1177/1069072706298156

Grasha, A. (1996). Teaching with style. Pittsburgh, PA: Alliance Publishers.

Grasha, A. F. (2002). Teaching with style: A practical guide to enhancing learning by understanding teaching and learning styles. San Bernadino, CA: Alliance Publishers.

Hobfoll, S. E., \& Shirom, J. (1993). Stress and burnout in the workplace: Conservation of Resources. In Golembiewski, R, T. (Ed). Handbook of organisational behaviour. New York: Dekker.

Kaplan, E. J., \& Kies, D. A. (1995). Teaching and learning styles: Which came first? Journal of Instructional Psychology, 22(1), 29-33.

Laub, A. (1998). Isolation in the secondary school as a predictor of teacher burnout. Unpublished doctoral dissertation, State University of New York, Albany.

Layman, E., \& Guyden, J. A. (1997). Reducing your risk of burnout. Health Care Supervisor, 15(3), 57-69. 
Hoseini Fatemi, A. \& Raoufi, R.

Mandaglio, S. (1984). The helping professional and teacher burnout. The south pacific Journal of Teacher Education, 12(1), 31-38. http://dx.doi.org/10.1080/0311213840120105

Maslach, C., \& Jackson, S. E. (1981). The measurement of experienced burnout. Journal of occupational behavior, 2, 99-13. http://dx.doi.org/10.1002/job.4030020205

Maslach, C., \& Jackson, S. (1984). Burnout in organisational settings. In Oskamp, S. (Ed). Applied social psychology annual. Application in organizational settings (pp. 133-153). Beverly Hills, CA: Sage.

Maslach, C., \& Jackson, S. E. (1981). MBI : Maslatch Burnout Inventory. Palto Alto, CA:Consulting psychological press.

Maslatch, C. \& Jackson, S.E. (1986). Maslach burnout inventory. Palto Alto, CA: Consulting Psychologist Press.

Maslach, C., Jackson, S. E., \& Leiter, M. P. (1996). Maslach burnout inventory manual (3rd ed.). Palo Alto: Consulting Psychologists Press.

Mukundan, J., \& Khandehroo, K. (2010). Burnout among English language teachers in Malaysia. Contemprary Issues in Education Research, 3(1), 71-76.

Pines, A., \& Aronson, E. (1988). Career Burnout: Causes and Cures ( $2^{\text {nd }}$ ed.) New York: Free Press.

Pishghadam, R. \& Sahebjam, S. (2012). Personality and emotional intelligence in teacher burnout. The Spanish Journal of Psychology. 15 (1), 227-236.

Schaufeli, W.B., Van Dierendonk D. \& Van Gorp, K. (1996). Burnout and reciprocity: towards a dual-level social exchange model. Work \& Stress, 10, 225-237.

Schaufeli,W., \& Enzmann, D. (1998). The burnout companion to study and practice: A critical analysis. London: Taylor \& Francis.

Shirom, A. (2003). Job-related burnout. In J. C. Quick \& L. E. Tetrick (Eds.), Handbook of occupational health psychology (pp. 245-265). Washington, DC: American Psychological Association. http://dx.doi.org/10.1037/10474-012

Sternberg, R. J. (1988). Mental self-government: A theory of intellectual styles and their development. Human Development, 31, 197-224. http://dx.doi.org/10.1159/000275810

Sternberg, R. J. (1997). Thinking styles. New York: Cambridge University Press. http://dx.doi.org/10.1017/CBO9780511584152

Whitehead, A. J. (2001). Teacher burnout: A study of occupational stress and burnout in New Zealand primary school teachers. Unpublished doctoral dissertation, Massey University, Albany, Auckland.

Zarei Matin, H. Seyyed Kalali, N., \& Akhavan Anvari, M. (2012). Do demographic variables moderate the relationship between job burnout and its consequences? Iranian Journal of Management Studies, 5, 47-62.

Zamani Rad, A., \& Nasir, R. (2010). Burnout and career self-concept among teachers in Mashhad, Iran, Procedia Social and Behavioral Sciences, 7, 464-469. http://dx.doi.org/10.1016/j.sbspro.2010.10.063

Zhang, L. F. (2004). Thinking styles: University students' preferred teaching styles and their conceptions of effective teachers. The Journal of Psychology, 138(3), 233-252. http://dx.doi.org/10.3200/JRLP.138.3.233-252

Zhang, L. F., \& Sternberg, R. J. (2005). A threefold model of intellectual styles. Educational Psychology Review, 17(1), 1-53. http://dx.doi.org/10.1007/s10648-005-1635-4

Zhang, L. F., Huang, J. F., \& Zhang, L. L. (2005). Preferences in teaching styles among Hong Kong and US university students. Personality and Individual Differences, 39, 1319-1331. http://dx.doi.org/10.1016/j.paid.2005.05.004

Zhang, L. (2007). Do personality traits make a difference in teaching styles among Chinese high school teachers? Personality and Individual Differences, 43, 669-679. http://dx.doi.org/10.1016/j.paid.2007.01.009

Zlatković, B., \& Petrović, D. (2011). Pre-service teacher training in Serbia: Analysis of the compatibility of teachers faculties curricula, Journal of Education, 60(4), 651-663. 